\title{
Systemic Risk in Commodity Markets: What Do Trees Tell Us About Crises?
}

\author{
Delphine LAUTIER ${ }^{1}$, Julien LING $^{1}$ and Franck RAYNAUD ${ }^{2}$ \\ ${ }^{1}$ Université Paris-Dauphine \\ ${ }^{2}$ Ecole Polytechnique Fédérale de Lausanne
}

4th April 2014

\begin{abstract}
We examine the impact, on commodity derivative markets, of two financial crises: the Subprime crisis and the bankruptcy of Lehman Brothers. These crises are "external" for commodity markets: they appeared in the financial sphere. Still, because now commodity markets are highly integrated, between themselves and with other financial markets, such events could have had an impact. In order to fully comprehend this possible impact, we examine prices fluctuations in three dimensions: the observation time, the space dimension - the same underlying asset can be traded simultaneously in two different places - and the maturity of the transactions. We first focus on the efficiency of the shocks propagation: does it improve during crises? Then we concentrate on the paths of shocks propagation: are they modified? How? Finally we focus on the centrality of the prices system: does it change? Does it increase?
\end{abstract}

JEL Codes: E44, F15, G01, Q02, Q40

Keywords: Commodity markets, financial markets, derivative markets, market integration, crises, graph theory, minimum spanning tree, centrality

This article is based upon work supported by the Chair Finance and Sustainable Development and the FIME Research Initiative.

\section{Introduction}

In this article we examine the impact of two financial crises on commodity derivative markets : the Subprime crisis and the bankruptcy of Lehman Brothers. These crises are 
exogenous for commodity markets: they appeared in the financial sphere. Still, because now commodity markets are highly integrated ${ }^{1}$, between themselves and with other financial markets, such events could have propagated. In order to fully comprehend their potential impact on commodity derivative markets, we examine prices fluctuations in three dimensions: the observation time, the space dimension - the same underlying asset can be traded in two exchanges simultaneously - and the maturity of the transactions. Moreover, we perform an event study: prices fluctuations are examined during a very short period of time, consisting in 10 days before and after those events, i.e. the $9^{\text {th }}$ of August 2007 and the $15^{\text {th }}$ of September 2008 (see the Appendices 4 and 5 for more details on the chronology of the Lehman and the Subprime crises).

Such an analysis requires the use of high dimensional data. In this context, the tools of the graph theory already proved to be very interesting ${ }^{2}$, first because they provide a way to synthesize the information contained in the data, second because they allow for meaningful visual representations. In our case, the nodes of the graph are prices returns: there is one node per futures contract and per maturity. The link between each pair of nodes depends on the correlations between prices returns.

In order to filter the information contained in the graphs, we use Minimum Spanning Trees - MST - (Mantegna1999). As they capture the most important links among the markets, they can be seen as the most probable and the most efficient paths of prices shocks transmission. Taking into account the length of the MST allows to ask a first question: does the efficiency of the prices shocks propagation improve during crises?

We then concentrate on the organization of the graph, namely the topology of the MST and ask a second question: do the paths of shocks propagation change during crises? How? In order to answer these questions, several tools are used. First, the survival ratios: they indicate the number of links that change from one day to the other and give indications about large reorganizations of the graphs. Second, the allometric coefficients allow to measure how far a tree stands from a linear or, on the contrary, a star-like organization. These two extreme configurations have radically opposite consequences on the systemic point of view: with a chain-like tree, if the shock appears at one extremity, it must go through all nodes before reaching the other extremity. On the contrary, with a star-like tree, one shock arising at the center of the graph might propagate extremely rapidly to all other nodes !

Finally, we focus on the centrality of the prices system: does it change? Does it increase? In a first approach, we simply identify the center of the price system as the most connected node. We then improve this analysis by importing a tool initially developed by

\footnotetext{
${ }^{1}$ See for instance (Buyukşahin et al.2010), (Buyukşahin and Robe2011), (Buyukşahin and Robe2013), (Tang and Xiong2011), (Irwin and Sanders2011).

${ }^{2}$ For portfolio management, market interactions, etc. See for instance (Onnela et al.2003), (CohenCole et al.2012), (Lautier and Raynaud2012).
} 
(Bonacich1987) for social networks: in a nutshell, this measure takes into account the numbers of (direct and indirect) neighbors of a node and their proximity.

In what follows, we first explain how to build a graph on the basis of our data. We then examine the efficiency of the shocks propagation, the organization of the price system and its centrality. At each step, we compare the behavior of the system on the whole period with what happened during the crises.

\section{The prices system}

After a short description of the data used for the study, we explain the way we built prices graphs.

\section{$2.1 \quad$ Data}

For the empirical study, we retained futures markets corresponding to three sectors: energy, agriculture and financial assets. On the basis of the Futures Industry Association's monthly volume reports, we selected the contracts characterized by the largest transaction volumes, over a long time period. Moreover, in the absence of reliable spot data for most commodity markets, we approximated all spot prices with the nearest futures prices. Such an approximation is very common in finance.

We used Datastream in order to collect settlement prices on a daily basis. Moreover, we rearranged the futures prices in order to reconstitute daily term structures, i.e. the relationship linking, at a specific date, several futures contracts with different delivery dates. Table 1 summarizes the main characteristics of our database.

With such a database, one of the difficulties comes from the fact that prices curves are shorter at the beginning of the period. Indeed, over time, the number of contract maturities usually rises on a derivative market. The growth in the transaction volumes of existing contracts results in the introduction of new delivery dates. Thus, in order to have continuous time series, we had to remove some maturities from the database. In the different graphs exhibited in this chapter, the number which is situated just after the name of the underlying asset represents the number of maturities that was kept. This number does not correspond to the transaction horizon of the longest contract, which is mentioned in Table 1.

Finally, when performing spatial and 3-D analyses, we had to retain the longest common time period for all underlying assets, between 2000 and 2009. Once these selections have been carried out, our database still contains more than 655, 000 prices. 


\begin{tabular}{|l|l|l|l|l|}
\hline Underlying asset & Exchange-Zone & Period & Maturities & Records \\
\hline \hline Light crude oil & CME-US & $1998-2009$ & up to 84 & 2965 \\
\hline Brent crude & ICE-EU & $2000-2009$ & up to 18 & 2523 \\
\hline Heating oil & CME-US & $1998-2009$ & up to 18 & 2835 \\
\hline Gasoil & ICE-EU & $2000-2009$ & up to 12 & 2546 \\
\hline Nat. gas $(U S)$ & CME-US & $1998-2009$ & up to 36 & 3140 \\
\hline Nat. gas $(E u)$ & ICE-EU & $1997-2009$ & up to 9 & 3055 \\
\hline \hline Wheat & CME-US & $1998-2009$ & up to 15 & 3026 \\
\hline Soy bean & CME-US & $1998-2009$ & up to 14 & 2977 \\
\hline Soy oil & CME-US & $1998-2009$ & up to 15 & 3056 \\
\hline Corn & CME-US & $1998-2009$ & up to 25 & 2569 \\
\hline \hline Eurodollar & CME-US & $1997-2009$ & up to 120 & 3056 \\
\hline Gold & CME-US & $1998-2009$ & up to 60 & 2877 \\
\hline Exchange rate $\in / \$$ & CME-US & $1999-2009$ & up to 12 & 2864 \\
\hline Mini SP500 & CME-US & $1997-2009$ & up to 6 & 3011 \\
\hline
\end{tabular}

Table 1: Main characteristics of the collected data: Nature of the assets, trading location (i.e. United States - US - or Europe - EU), time period, longest maturity (in months). CME stands for Chicago Mercantile Exchange, ICE for Inter Continental Exchange.

\subsection{Building a graph}

Our graphs are built on the basis of correlations between price returns. This is the measure we retained in order to capture the synchronous prices moves in the system. In order to build a graph, these correlations are transformed into distances.

Correlations of prices returns The first step towards the analysis of market integration is the computation of the synchronous correlation coefficients of price returns $\rho_{i j}(t)$, defined as follows:

$$
\rho_{i j}(t)=\frac{\left\langle r_{i} r_{j}\right\rangle-\left\langle r_{i}\right\rangle\left\langle r_{j}\right\rangle}{\sqrt{\left(\left\langle r_{i}^{2}\right\rangle-\left\langle r_{i}\right\rangle^{2}\right)\left(\left\langle r_{j}^{2}\right\rangle-\left\langle r_{j}\right\rangle^{2}\right)}},
$$

In the spatial dimension, $i$ and $j$ stand for the nearby futures prices of pairs of assets (like crude oil or corn), whereas they stand for pairs of delivery dates in the maturity dimension. They are a mix of the two in the three-dimensional analysis. The daily logarithm price differential stands for price returns $r_{i}$, with $r_{i}=\left(\ln F_{i}(t)-\ln F_{i}(t-\Delta t)\right) / \Delta t$, where $F_{i}(t)$ is the price of the futures contract $i$ at date $t . \Delta t$ is the time interval and 〈.) denotes the statistical average performed over time, on the trading days of the study period.

For a given time period and a given set of data, we thus computed the matrix of $N \times N$ 
correlation coefficients $C$, for all the pairs $i j$. $C$ is symmetric with $\rho_{i j}=1$ when $i=j$. Thus, it is characterized by $N(N-1) / 2$ coefficients.

In order to perform dynamical studies on the basis of rolling windows, we had to select the proper window length. We wanted it to represent typical economic periods (one semester, one year, five years...) and to be as short as possible, in order to give evidence of sudden changes. We were also confronted to a technical constraint: to get representative results, the number of observations must be larger than the number of nodes. With 220 series of prices returns (i.e. 220 nodes), we thus retained a rolling window of one year (252 trading days).

Finally, we work with rolling windows situated before the observation date. So when we look at what happens on the $9^{\text {th }}$ of August 2007, the information used is the one corresponding to one year before that event. Fortunately, as our two crises are separated by more than one year, there is no overlap between them.

From correlations to distances In order to use the tools of the graph theory, we needed to introduce a metric. The correlation coefficient $\rho_{i j}$ indeed cannot be used as a distance $d_{i j}$ between $i$ and $j$ because it does not fulfill the three axioms that define a metric ((Gower1966)):

- $d_{i j}=0$ if and only if $i=j$,

- $d_{i j}=d_{j i}$

- $d_{i j} \leq d_{i k}+d_{k j}$

A metric $d_{i j}$ can however be extracted from the correlation coefficients through a nonlinear transformation. Such a metric is defined as follows ${ }^{3}$ :

$$
d_{i j}=\sqrt{2\left(1-\rho_{i j}\right)}
$$

A distance matrix $D$ was thus extracted from the correlation matrix $C$ according to Equation (2). $C$ and $D$ are both $N \times N$ dimensional. While the coefficients $\rho_{i j}$ can be positive for correlated returns or negative for anti-correlated returns, the distance $d_{i j}$ representing the distance between price returns is always positive. This distance matrix corresponds to a full connected graph: it represents all the possible connections in the prices system.

\footnotetext{
${ }^{3}$ With such a definition of the distance - even if it is perfectly straightforward - one might ask if it would be relevant (or not) to take the square of $\rho_{i j}$; the answer is twofold: first, according to us, as we do not examine diversification issues but shocks, this would not be interesting; second, this change has no impact on our results (computations are available upon request to the authors)
} 


\section{The efficiency of the shocks transmission}

Considering the dimensionality of our prices system and the number of nodes in our graph, it would be very difficult to visualize it. We thus resort to a filtering technique which is especially suited in our context: the Minimum Spanning Tree (MST). In what follows, we first explain how to obtain such a graph and what it looks like. As the MST can be considered as the most efficient path for a prices shock transmission, we then study its behavior.

\subsection{The minimum spanning tree}

In order to understand the organizing principles of a system through its representation as a graph, the latter needs to be spanned, i.e. all its nodes must have at least one connection. There are however a lot of paths spanning a graph. For a weighted graph like ours, the minimum spanning tree (MST) is the one spanning all the nodes, without loops. It has less weight than any other tree.

Through this filtering procedure (the information space is reduced from $N(N-1) / 2$ to $(N-1))$, the MST reveals the most relevant connections of each element of the system. In our study, it provides the shortest path linking all nodes. Thus, it can be seen as a way of revealing the underlying mechanisms of systemic risk: the minimum spanning tree is the easiest path for the transmission of a prices shock.

The visualization of the trees is a very important step, as it addresses the meaningfulness of the taxonomy that emerges from the system. ${ }^{4}$ Figure 1 presents the MST obtained on the basis of our price system, for the spatial dimension and on the whole period. It is scaled: the closest nodes correspond to the most correlated price series. Three sectors can be identified: energy is at the top left-hand. It gathers American as well as European markets and is situated between agriculture (on the right) and financial assets (at the bottom).

At first glance (if we consider that the number of links allows for identifying the center of the graph), the most connected node is the one corresponding to the Brent crude oil, which makes it - a priori - the best candidate for the transmission of price fluctuations in the tree (actually, the same could have been said for the American crude oil - Light Crude - as the distance between these products is very short). Last but not least, the energy sector seems the most integrated, as the distances between the nodes are short.

\footnotetext{
${ }^{4}$ Before going further, let us make two remarks: first, we are considering links between markets and/or delivery dates belonging to the MST. Thus, if a relationship between two markets or maturities does not appear in the tree, it does not mean that this relation does not exist. It just does not correspond to a minimal distance. Second, our results naturally depend on the nature and number of markets chosen for the study.
} 


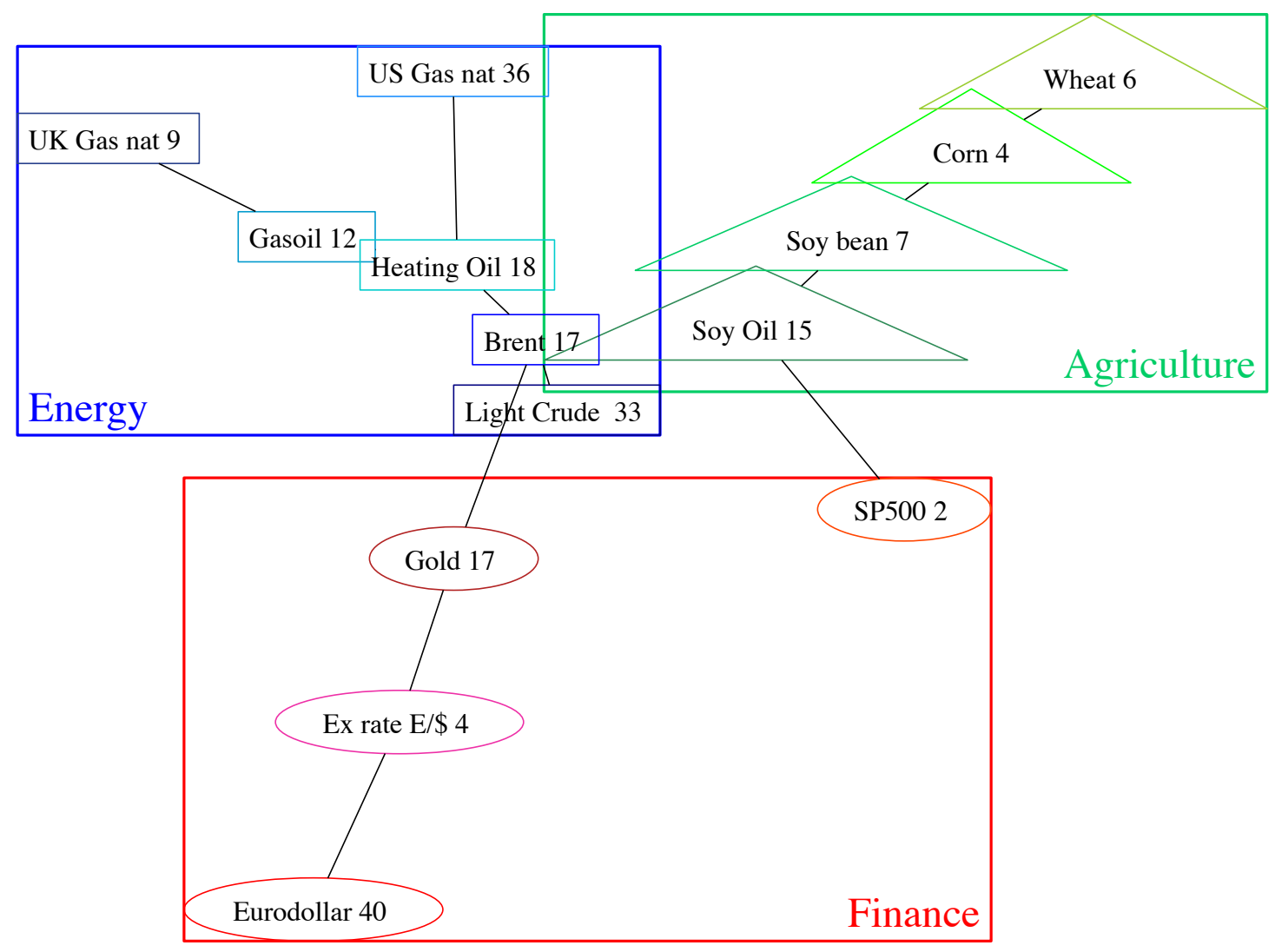

Figure 1: Scaled MST in the spatial dimension, 2000-2009.

The link between the energy and agricultural products passes through soy oil. This is interesting, as the latter can be used for fuel. The link between commodities and financial assets passes through gold, which is also meaningful, as gold can be seen as a commodity but also as a reserve of value. The only surprise comes from the S\&P500, which is more correlated to soy oil than to financial assets. ${ }^{5}$

Such a star-like organization leads to specific conclusions regarding systemic risk. A prices move appearing in the energy markets, situated at the heart of the price system, will have more impact than a fluctuation affecting peripheral markets such as interest rates or wheat. This explains why we consider the Subprime and the Lehman crises as exogenous events in this study.

The 3D MST, depicted by Figure 2 is less easy to read, but it can be interpreted through the prism of the spatial tree. The same topology remains, except that adding maturities introduces linear branches around each market (with the noticeable exception of the

\footnotetext{
${ }^{5}$ Compared to all other futures contracts taken into account in this study, the S\&P500 is however the less actively traded. In a dynamic analysis, it appears that the correlation of this contract with the others is very unstable. The same is true, of course, for the connections between the S\&P500 and the other nodes.
} 
American natural gas). Moreover, this scaled representation shows that some markets are more integrated than the others: clusters of maturities can be seen, at the center of the graph, for the energy sector (except for the two natural gases). A strong integration can also be observed in the financial branch; this is especially true for the eurodollar contract after the $8^{\text {th }}$ maturity.

Because these topologies are very stable through time (Lautier and Raynaud2012), we will use them as references in the remaining of this study.

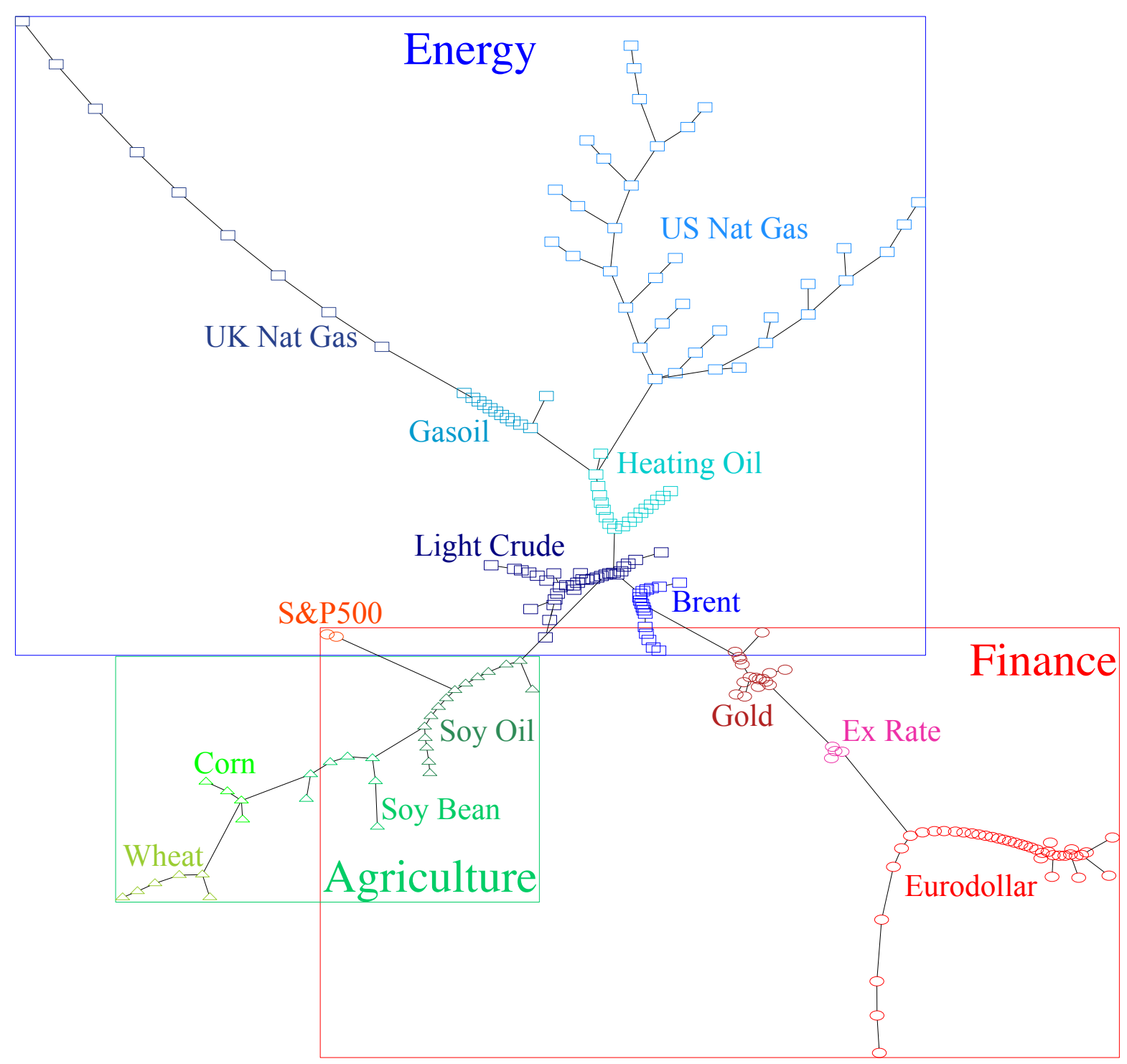

Figure 2: Scaled MST in 3D on the whole sample

\subsection{How does the length of the MST behave?}

We first explain how this measure can be obtained and how it behaves on the whole sample. We then study it around crises. 


\subsubsection{The measure}

The normalized tree length can be defined as the sum of the lengths of the edges belonging to the MST:

$$
\mathcal{L}(t)=\frac{1}{N-1} \sum_{(i, j) \in M S T} d_{i j},
$$

where $t$ denotes the date of the construction of the tree and $N-1$ is the number of edges in the MST. The length of a tree is longer when the distances increase and consequently when correlations are low. Thus, the more the length shortens, the more integrated the system is.

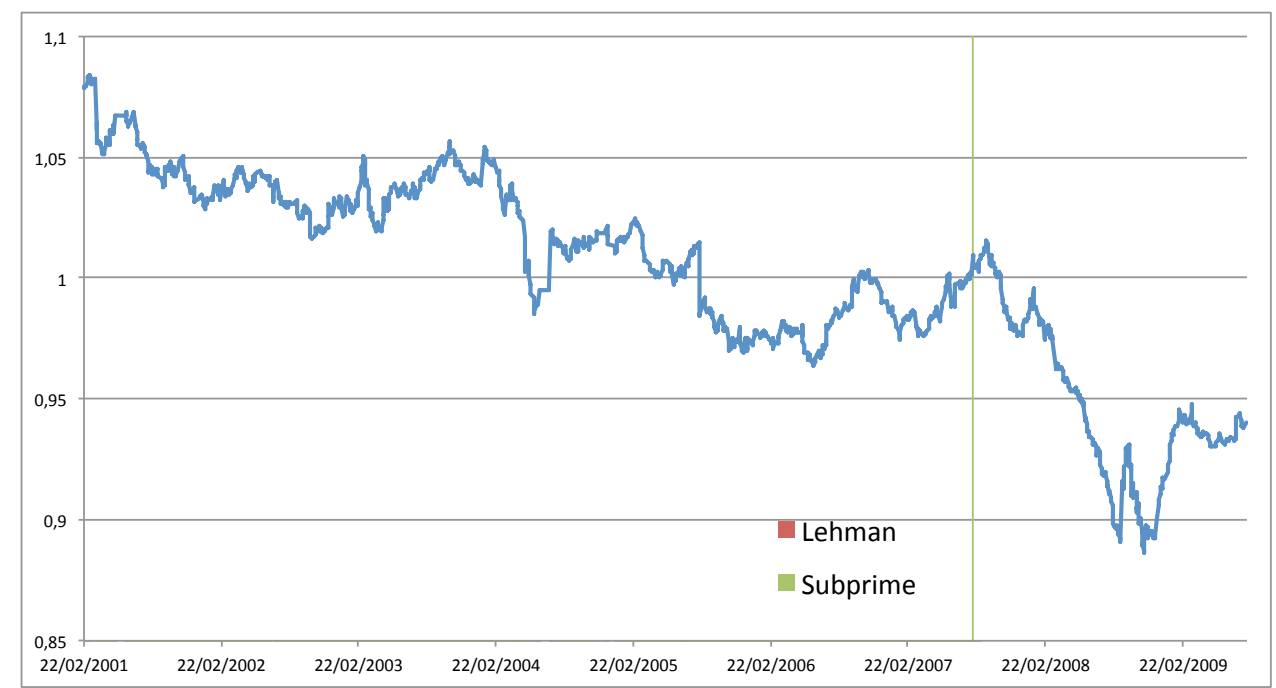

Figure 3: Normalized tree length in spatial dimension

Figure 3 represents the dynamic behavior of the normalized length of the MST in the spatial dimension, on the whole period under consideration. The general pattern is that the length decreases, which reflects the increasing integration of the system. Thus the most efficient transmission path for price fluctuations becomes shorter as time goes on. A more in-depth examination of the graph also shows some very important moves at specific dates, one of them being around the Lehman crisis: this is what interests us now.

\subsubsection{The length of the trees around the crises}

Before analyzing the evolution of the length, we wanted to know whether the changes that occurred around the crises were tail events or not. We thus computed the empirical distribution of the length variations over the whole period and we checked the frequency of occurrence of variations above (for increases) or below (for decreases) those observed during the crises. The results are that at $5 \%$, only the changes recorded on August $16^{\text {th }}$, 2008 (i.e. Subprime +5 trading days) and on September, the $12^{\text {th }}$, 2008 (i.e. Lehman-1 trading day) are in the tail (both in spatial dimension and 3D). In the spatial dimension, 


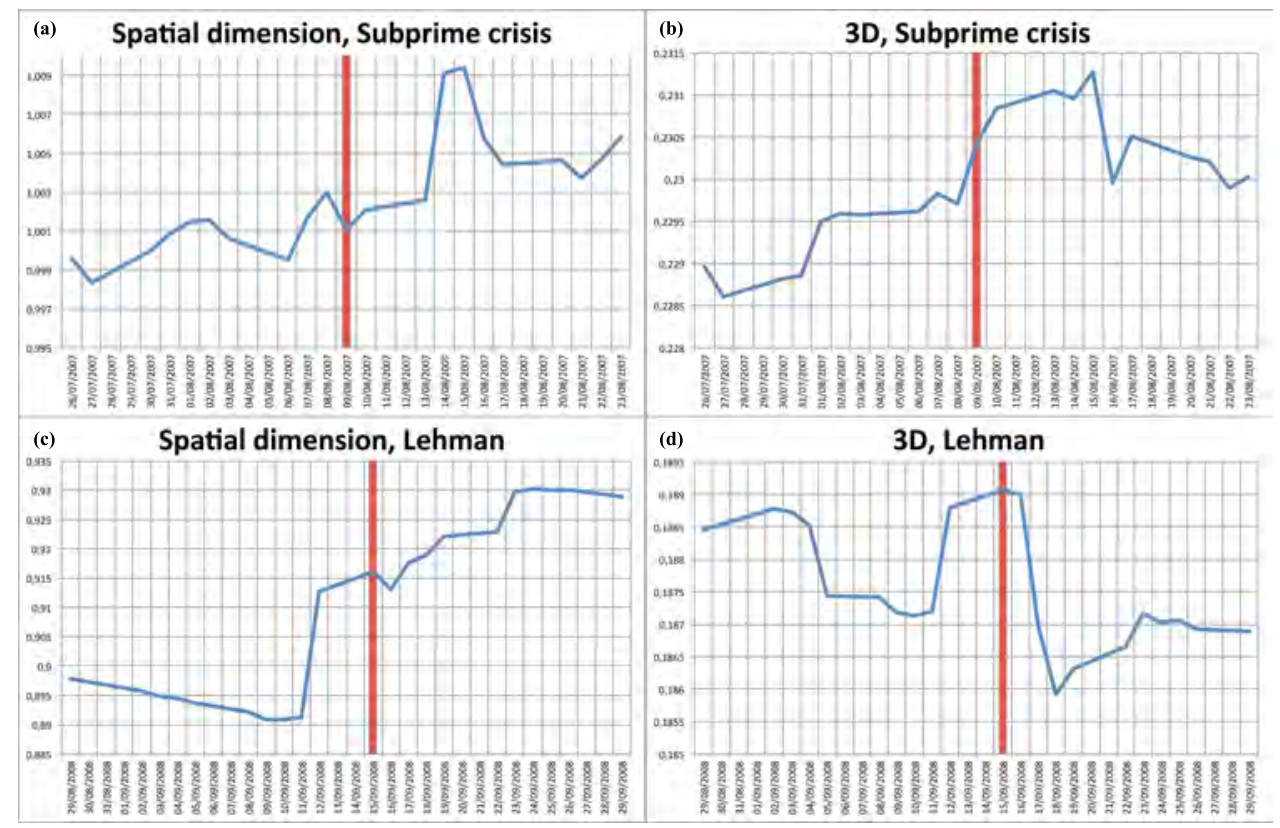

Figure 4: Normalized tree length in spatial dimension and 3D for each event

we can add the $14^{\text {th }}$ August 2007 (i.e. Subprime+3) and in 3D, the $17^{\text {th }}$ September 2008 (i.e. Lehman +2 ). Let us also note that those last two events, plus the one recorded on September the $12^{\text {th }} 2008$, have a very low frequency (below or close to $1 \%$ ). Therefore, we can conclude that these crises have been exceptional events over our database period, and that the length of window retained for our event study, ie 10 days before and after the crises is sufficient.

Figures 4 (a) to 4 (d) represent the evolution of the length of the trees around the two crises under consideration, both in the spatial dimension and in 3D. We can see that in each case, the length of the tree rises around the Events: for the Subprime crisis, the peak appears on August the $15^{\text {th }}$, at Event +4 trading days. For the Lehman, the change in the behavior of the tree arrives before the Event, between the $11^{t h}$ and the $12^{\text {th }}$. This corresponds to the period when the difficulties encountered by Lehman became public knowledge (see the Appendices 4 and 5).

Such a result apparently contradicts that of (Chakraborti et al.2003) who, working on the Black Monday of the $19^{\text {th }}$ October 1987, observe a drop in the length of their MST. However a closer look at our trees shows that the increase of the global length goes with a decrease on certain parts of the graph. This is the case, especially, for the Eurodollar market around Lehman, as shown by Figure 5. There is clearly a shrink in the tree at this occasion.

To summarize, even if our price system becomes more and more integrated between 2000 and 2009, these two crises, born in the financial sphere, did not harm the commodity markets as a whole. These events had, as expected, an impact on the financial sphere: there is a local increase of the integration for the financial assets. The same is not true, 
however for commodity markets: they are momentarily less connected with the financial assets. This is of course a very global result. We will go further by examining the organization of the MST around these dates.
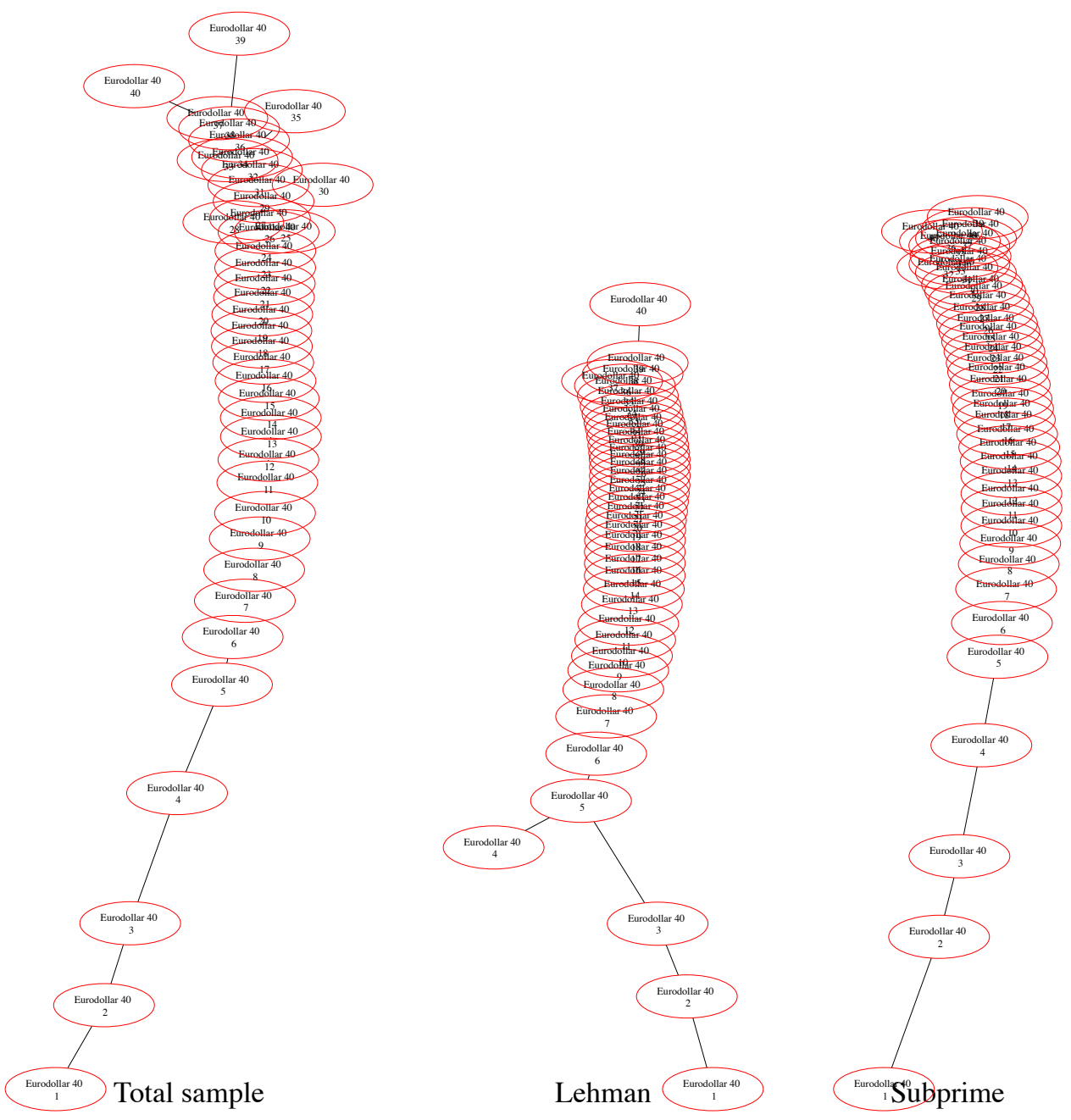

Figure 5: Focus on the Eurodollar market, on the whole sample, around the Subprime crisis, around the Lehman crisis

\section{The organization of the tree}

Measuring the length of the MST does not give the possibility to ask whether or not the paths for shocks propagation change during crises. In order to answer this question, the graph theory provides several tools: first the survival ratios, second the allometric coefficients. 


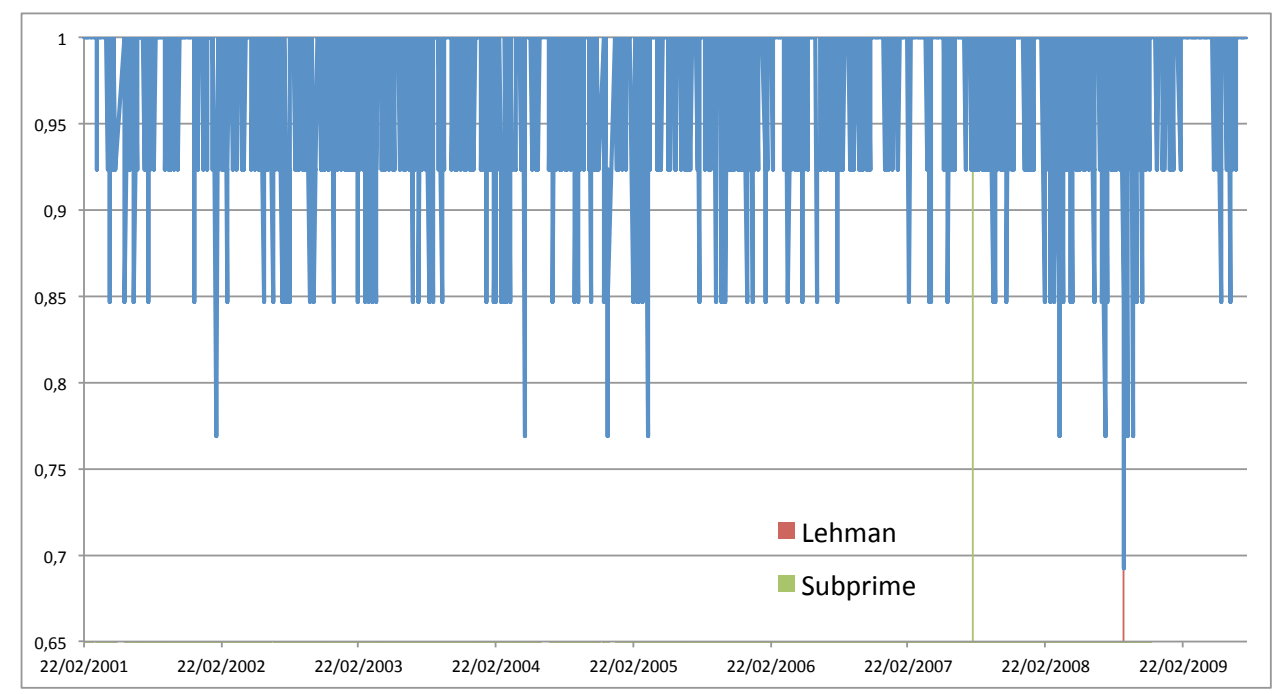

Figure 6: Survival ratios in the spatial dimension, on the whole period

\subsection{The survival ratios}

This measure $\left(S_{R}\right)$ indicates the fraction of links that survives, in the MST, between two consecutive trading days ((Chakraborti et al.2003)):

$$
S_{R}(t)=\frac{1}{N-1}|E(t) \cap E(t-1)| .
$$

In this equation, $E(t)$ refers to the set of the tree edges at date $t, \cap$ is the intersection operator and $\mid$. $\mid$ gives the number of elements contained in the set. Under normal circumstances, the topology of the trees, between two dates, is very stable in the spatial dimension as well as in 3D, as pictured by Figure 6 which shows first, that most of the time more than 85 percent of the links remain unchanged from one day to the other, and second that the Lehman bankruptcy is a very specific event. This is far less obvious for the Subprime crisis.

The use of this measure naturally raises the same question than before: are the values observed around the crises exceptional? As before, we thus evaluated the frequency of occurrence of high reconfigurations of the graph. Since the ratios are discrete values (due to the finite number of links), we have discrete statistics. We find that only the changes on September $18^{\text {th }}-19^{\text {th }}, 2008$ (the $17^{\text {th }}$ is close) are below the $5 \%$ frequency in spatial dimension (more than three changes). In 3D, only September $17^{\text {th }}$ and $24^{t h}, 2008$ appear below the $5 \%$ threshold (more than five changes). We can thus conclude that the events of September $17^{\text {th }}, 2008$ have been exceptional. According to these figures, the Subprime crisis has nothing specific. Even if the tree locally shrinks in the financial sphere, the paths of shocks transmission remains the same.

As far as the Lehman crisis is concerned, if we now go back to our event study, both in the spatial dimension and in $3 \mathrm{D}$, we can see that the most important reorganizations 
appear in the spatial dimension, where more than 30 percent of the graph is reorganized. Note finally that, while some fluctuations of the survival ratios might be due to real changes in the behavior of the system, it is worth noting that others may simply be due to noise. This is why a deeper analysis is needed. We will perform it through the use of allometric coefficients.

\subsection{The allometric coefficients}

The computation of the allometric coefficients of a MST provides a means of quantifying where this tree stands between two asymptotic topologies: star-like trees, which are symptomatic of a random organization, and chain-like trees, which reveal a strong ordering in the underlying structure.

The first model of the allometric scaling on a spanning tree was developed by (Banavar et al.1999). The first step of the procedure consists in initializing each $A_{i}$ of the nodes of the tree with the value 1 . Then the root or central vertex of the tree must be identified. In what follows, the root is defined as the node having the highest number of links attached to it ${ }^{6}$. Starting from this root, the method consists in assigning two coefficients $A_{i}$ and $B_{i}$ to each node $i$ of the tree, where:

$$
A_{i}=\sum_{j} A_{j}+1 \text { and } B_{i}=\sum_{j} B_{j}+A_{i}
$$

$j$ stands for all the nodes connected to $i$ in the MST. The allometric scaling relation is defined as the relationship between $A_{i}$ and $B_{i}$ :

$$
B \sim A^{\eta}
$$

$\eta$ is the allometric exponent. It represents the degree or complexity of the tree and stands between two extreme values: $1^{+}$for star-like trees (Figure 7 ) and $2^{-}$for chain-like trees (Figure 8).

The structure of the MST will have, of course, dramatic consequences in terms of shocks propagation; a star-like tree will ease propagation: all markets can be affected in a maximum of two steps. Comparatively, a chain-like topology needs $N-1$ steps, from one end to the other.

Studies made on the basis of allometric coefficients, on the whole period, have shown that the maturity dimension of the MST is almost linear, whereas the organization of the tree in the spatial dimension stands right in the middle of the two extreme configurations. Finally, merging the two in a 3-D analysis leads to allometric coefficients around 1.75.

\footnotetext{
${ }^{6}$ As a robustness check, we also performed the analysis when the root is identified with the Bonacich's measure. The results remain qualitatively the same. They are available upon request.
} 

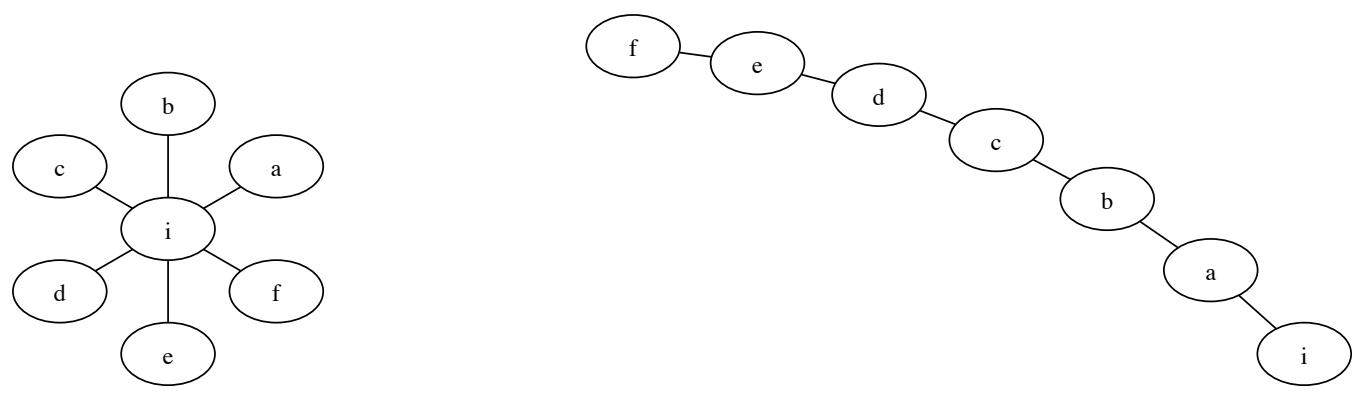

Figure 7: Star-like structure

Figure 8: Chain-like structure

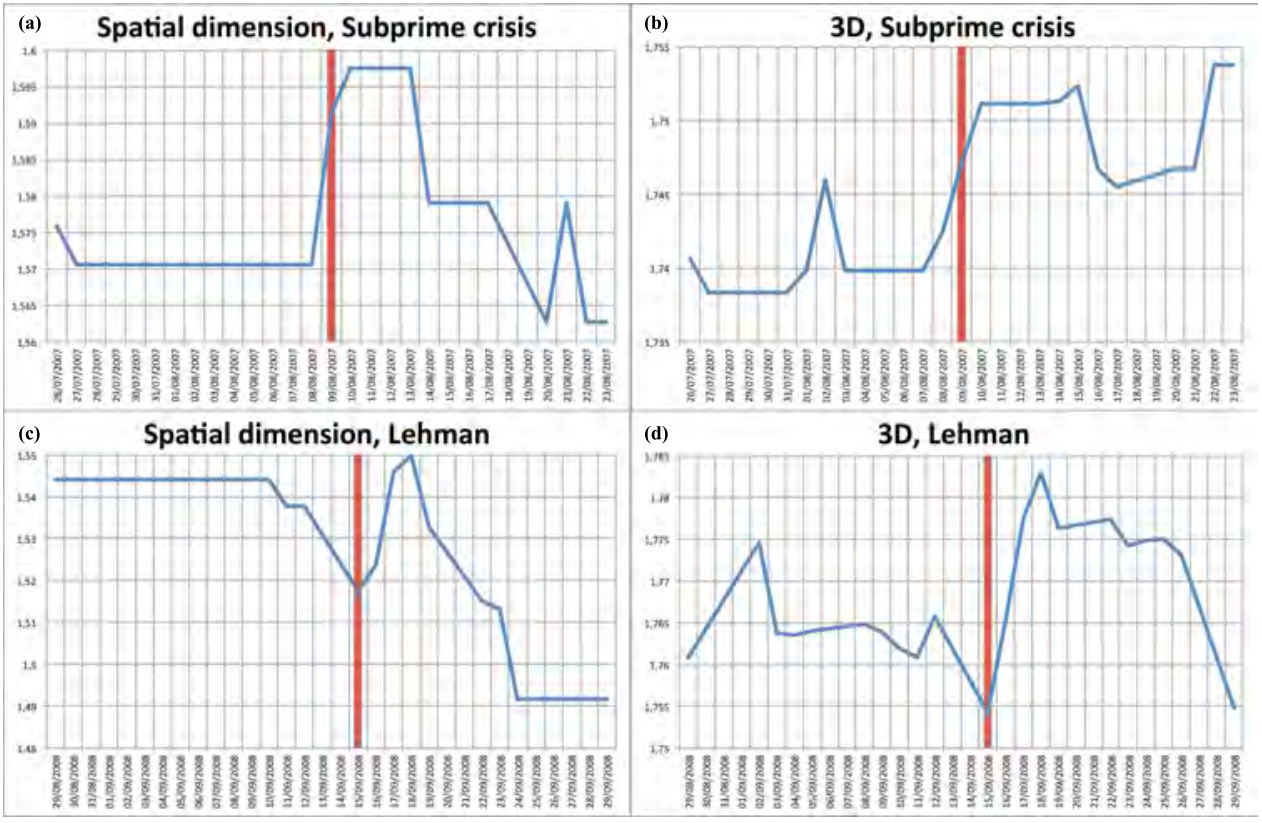

Figure 9: Allometric coefficients, in spatial dimension and in 3D, for each event

If we look closely at what happens around the crises, a first comment is that the values of the allometric coefficients around both two events are notexceptional. A second comment is that, as depicted by Figure 9, we can observe a linearization of the trees. Such an observation pleads in favor of moderate fears, as far as the propagation of external shocks in the prices system is concerned: a linearization should indeed slow the transmission of prices shocks.

\section{Examining the centrality of the graph}

When studying systemic risk, it is important to correctly detect the center of the tree. For regulatory authorities, such nodes can be assimilated to regions of higher fragility. Even if we examine exogenous events in this study, the question of centrality remains crucial. 
What if these events create shocks attaining the center of the graph? They would then spread everywhere.

The most common way to identify the center of the graph is to assess its connectivity: we thus first consider the degree of each node (namely the number of connections) in the trees. Such an analysis however, might be insufficient, first because it does not take into consideration the distances between the nodes, second because it only takes into account the direct neighbors of a node. It could be interesting, on the contrary, to be mindful of the overall configuration of the graph.

In what follows we first give an example of an analysis based on connectivity only, towards the evolution of the tree in the spatial dimension around the Lehman bankruptcy (as noted on the basis of the survival ratios, there is an important reconfiguration of the graph on this occasion). We then enrich the study with a new notion of centrality, initially proposed for social networks by Bonacich in 1987, and recently used by (Bloch and Quérou2013). To the best of our knowledge, it is the first time that such a method is employed in finance.

\subsection{The degree of the nodes}

In order to visualize the problem, let us go back to the MST in the spatial dimension around the Lehman case. This MST is depicted by Figure 10. If we compare this tree to the "normal one", depicted by Figure 1, we can evidence some changes: the S\&P500 has moved from soy oil to wheat; the UK natural gas is not directly connected to the energy sector anymore; more importantly, the gold is now at the center of the graph. Instead of being situated in the financial branch, making the links between the energy markets and the purely financial sphere, this node is now the most connected. It stands at the heart of the whole price system.

On a economic point of view, such a result is nicely intuitive. In the case of a high uncertainty affecting the whole financial system, we indeed expect investors to consider gold as a reserve of value. Yet the story is not so simple.

\subsection{The Katz-Bonacich centrality measure}

We first present the method itself, then use it for our event study. 


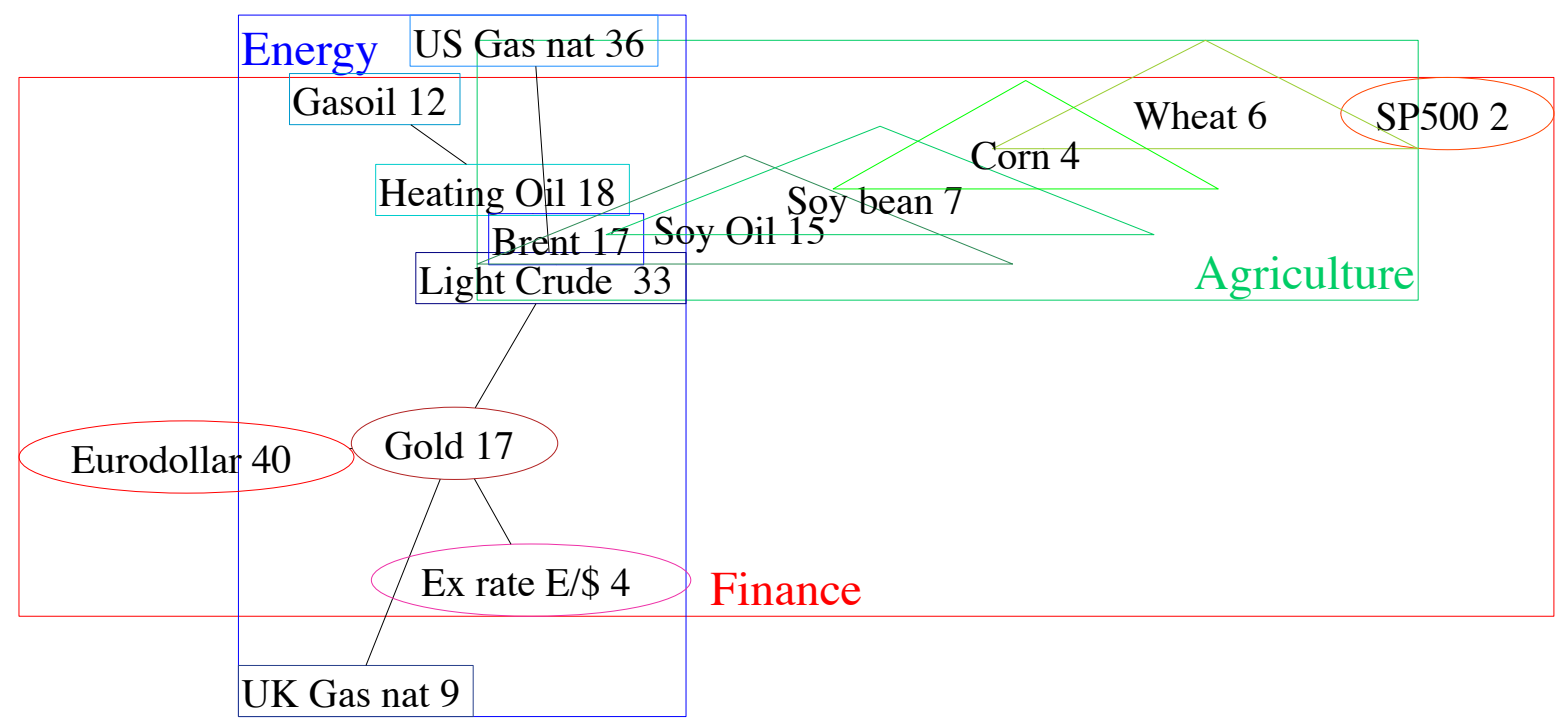

Figure 10: Scaled MST in Spatial dimension at Lehman

\subsubsection{The method}

Looking only at the direct neighbors of a node, as done when relying on the connectedness, may reveal insufficient, as illustrated by Figure 11: the nodes labelled "E" exhibit the highest connectivity (with a degree 4) but obviously, the " $\mathrm{D}$ " node is the most central.

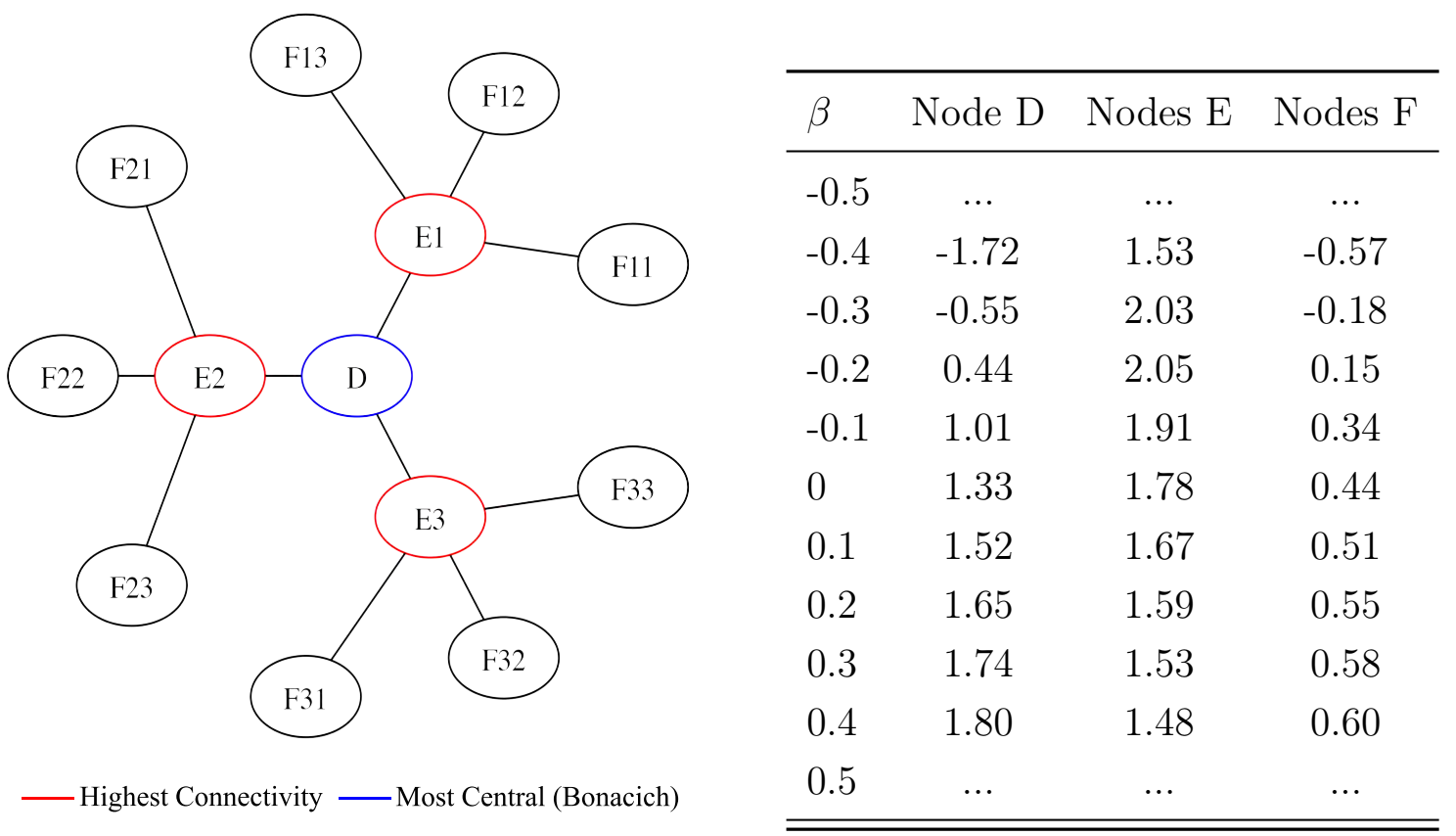

Figure 11: Degree vs. Bonacich's centrality Table 2: Centrality values for Figure 11

In order to take account of such phenomenon, (Bonacich1987) proposes a measure which is an extension of the one developed by (Katz1953). While Katz proposed a measure that did not take into consideration "negative" relations (if the value of a node 
increases, its neighbors' value decreases), the method of Bonacich allows to consider not only the direct neighbors of a node, but also all the indirect neighbors (thus taking into account the whole configuration of the graph) and negative relations. Based on a square relationship matrix $\mathbf{R}$, the centrality vector (one value per node) is computed as follows:

$$
c(\alpha, \beta)=\alpha(\mathbf{I}-\beta \mathbf{R})^{-1} \mathbf{R} \mathbf{1}
$$

with $\mathbf{I}$ the identity square matrix and $\mathbf{1}$ a vector of $1 \mathrm{~s}$.

The coefficient $\alpha$ is only a scale factor, but could be computed as the solution of the equation: $\sum_{i} c_{i}(\alpha, \beta)^{2}=N$ for more results (see below). For Bonacich, the coefficient $\beta$ can be interpreted in different ways: "the degree to which an individual's status is a function of the statuses of those to whom he or she is connected" or "a radius within which the researcher wishes to assess centrality".

Table 2 reproduces the centrality measures (source: (Bonacich1987)) for the graph depicted by Figure 11. Note that when the $\beta$ is negative, a node $i$ will have power, detrimental to its neighbors when the latter are weak (this could be a bargaining power for example). Therefore, the more weak neighbors it has, the more power it will have. Hence the higher centrality for nodes $\mathrm{E}$ compared to node $\mathrm{D}$ in such situation. If $\beta$ is equal to zero, the centrality measure gives the same result as the degree of the nodes. Finally, when $\beta$ becomes positive, the centrality of the node $\mathrm{D}$ rises. It can become higher than that of the nodes $\mathrm{E}$ (here when $\beta>0.2$ ).

The use of this method on the MST correlation matrix simplifies its application. The MST correlation matrix can indeed be directly identified to $\mathbf{R}$, since it fits the requirements: the $R_{i j}$ are positive and measure similarity, and the $R_{i i}$ are zeros. This is more precise than using the edge relationship (matrix of 0 s and $1 \mathrm{~s}$ when there is an edge between $i$ and $j$ ), because it allows to take into account the specific value of each link, instead of averaging them into a $\beta$ coefficient (which we thus drop).

\subsubsection{Empirical results}

The first check we did with this new measure of centrality was to come back on the configuration commented upon on section 3, represented by Figure 1. This is interesting: at the first glance, the crystallization of all fears should be on crude oil. Taking into consideration the overall configuration of the graph, as made in Table 3 leads to put more emphasis on petroleum products and on the energy sector as a whole. Moreover, a analysis of the centrality evolution between 2000 and 2009 shows that, especially after August $17^{\text {th }}$, 2005, the agricultural markets play a more important role. Such result call for further analysis. We however leave this for future empirical studies. 


\begin{tabular}{rrr}
\hline Market & Centrality measure & Rank \\
\hline Heating Oil & 1.148228 & 1 \\
Brent & 1.108484 & 2 \\
Light Crude & 0.856703 & 3 \\
Gasoil & 0.591487 & 4 \\
US Natural Gas & 0.364067 & 5 \\
Gold & 0.231502 & 6 \\
Exchange Rate $€ / \$$ & 0.036973 & 7 \\
UK Natural gas & 0.034241 & 8 \\
Eurodollar & -0.00875 & 9 \\
S\&P500 & -0.189855 & 10 \\
Wheat & -1.144788 & 11 \\
Soy Oil & -1.159204 & 12 \\
Corn & -1.890017 & 13 \\
Soy Bean & -1.979338 & 14 \\
\hline
\end{tabular}

Table 3: Bonacich's centrality measure for markets in spatial dimension using the whole database

Going back to the crises and looking at what happens in the spatial dimension, it seems again that the Subprime crisis did not affect much the organization (see, in the Appendix, the Table 8). On the contrary, the Lehman's bankruptcy seems to have had an impact (see, in the Appendix, the Table 11), mostly temporarily, though. Just after this event, the ranking of the nodes, according to the Bonnacich measure, puts the light crude first, the heating oil second, and the gold third. Gold becomes thus more important in crises times, which is intuitive. This means also, however, that this node becomes more dangerous.

In $3 \mathrm{D}^{7}$, the most central nodes are about the same as in the spatial dimension. As before, we do not find many changes around the Subprime crisis and many more around the Lehman bankruptcy.

First, when we compute the scale factor $\alpha$ as (Bonacich1987) recommends, we can compare centrality values to 1 to assess whether they are unusually high or low. When we do this in the spatial dimension, half of our markets never reach a centrality value above 1. ${ }^{8}$ They become thus less important. Second, if we consider the evolution of centrality,

\footnotetext{
${ }^{7}$ We cannot display the tables in this case due to the large number of nodes (220), but results are available upon request

8 The markets under consideration are the eurodollar, the exchange rate, the S\&P500, gold, gasoil, US and UK natural gases.
} 
we observe that the former central nodes become much less central, while the former less central become much more central. We interpret this result as a change in the direction of the propagation path. The most illustrative example is that of light crude: before the crisis, some of its maturities are among the most central nodes (say above rank 20), while others are among the least central (below rank 200). Suddenly, those least central become the most central ones (reaching as high as rank 1) and the most central ones get as low as rank 220 (on 220 nodes). Things then revert, later, back to the initial state. We thus observe on this occasion a radical change in the path of propagation, from the longest maturities to the shortest ones (or the opposite, depending on initial state), while normally, the spot market should drive the paper market.

\section{Conclusion}

Since a decade, commodity derivative markets have been experiencing a process of financialization, due to managers in the seek for the diversification of their portfolios and to the arrival of new actors on these markets. Such phenomenon has raised questions and worries about the eventuality of meaningless links, on an economic point of view, between commodities and more traditional financial markets like bonds and stocks. Those fears have been largely confirmed by the acknowledgment of a growing integration between commodity markets and with other financial markets. One could have even wonder to what extent a shock originating from financial markets could propagate to commodities and strongly impact them; investigating such a question is the purpose of this article.

To this aim, we focus on the impact on commodity markets of two recent crises from financial markets, namely the Subprime crisis and Lehman Brothers' bankruptcy. Using the insightful tools of the graph theory, we show that in spite of the fears growing from commodities integration, those shocks did not affect them as hard as one would expect, even though we do find some changes.

\section{References}

Banavar, J. R., Maritan, A., And Rinaldo, A. 1999. Size and form in efficient transportation networks. Nature 399:130-132.

Bloch, F. And Quérou, N. 2013. Pricing in social networks. Games and Economic Behavior.

Bonacich, P. 1987. Power and centrality: A family of measures. American Journal of Sociology 92:1170-1182. 
Brunnermeier, M. K. 2009. Deciphering the liquidity and credit crunch 2007-2008. Journal of Economic Perspectives 23:77-100.

Buyukşahin, B., Haigh, M. S., And Robe, M. A. 2010. Commodities and equities: ever a "market of one"? Journal of Alternative Investment pp. 76-95.

Buyukşahin, B. And Robe, M. A. 2011. Does Paper Oil Matter? Energy Markets'Financialization and Equity-Commodity Co-Movements. Working Paper, American University, (Revised) July .

Buyukşahin, B. And Robe, M. A. 2013. Speculators, Commodities and Crossmarket Linkages. Journal of International Money and Finance .

Chakraborti, A., Kaski, K., Kertész, J., and Onnela, J.-P. 2003. Dynamic asset trees and black monday. Physica A 324:247-252.

Cohen-Cole, E., Kirilenko, A., Patacchini, E., Fouque, J., and Langsam, J. 2012. Strategic interactions on financial networks for the analysis of systemic risk. Handbook on Systemic Risk p. 306.

Gower, J. C. 1966. Some distance properties of latent root and vector methods used in multivariate analysis. Biometrika 53:325-338.

IrWIN, S. H. AND SANDERs, D. R. 2011. Index funds, financialization, and commodity futures markets. Applied Economic Perspectives and Policy 33:1-31.

KATz, L. 1953. A new status index derived from sociometric analysis. Psychometrika 18:39-43.

Lautier, D. And Raynaud, F. 2012. Systemic risk in energy derivative markets: A graph-theory analysis. The Energy Journal 33:215-239.

Mantegna, R. N. 1999. Hierarchical structure in financial markets. The European Physical Journal B 11:193-197.

Onnela, J.-P., Chakraborti, A., Kaski, K., Kertesz, J., And Kanto, A. 2003. Dynamics of market correlations: Taxonomy and portfolio analysis. Physical Review E 68:056110.

TAng, K. And Xiong, W. 2011. Index Investing and the Financialization of Commodities. NBER, Working Paper No. 16325. 


\section{A Timelines around the events}

\section{A.1 Some important events around the Subprime crisis}

Based on (Brunnermeier2009), News feeds, Wikipedia

\begin{tabular}{ll}
\hline Date & Events \\
\hline S-10 & - Home sales declined and largest home builder reported loss \\
S-7 & - American Home Mortgage Investment Corp. faces difficulties \\
S-6 to S & - Quantitative hedge funds suffered losses, triggering margin calls, fire sales and \\
& correlation across strategies \\
S-6 & - US Crude oil prices reach a new high due to declining stocks and decreased output \\
S-4 & - Officials state that the housing crisis should not spread \\
S-3 & - America Home Mortgage Investment Corp. goes bankrupt \\
S & - BNP Paribas froze redemption of 3 of its investment funds due to inability to value \\
& structured products \\
& - Triggered the first illiquidity wave on the interbank market and support from \\
& Central Banks \\
S +1 & - Decreases propagate to Asian markets, triggering support from Central Banks \\
S +2 to S +8 & • Central Banks increase their support and lower rates \\
\hline
\end{tabular}

Table 4: Important events around the Subprime crisis ( $\mathrm{S}$ denotes the date of the trigger of the crisis, on August $9^{\text {th }}, 2008$ ) 


\section{A.2 Some important events around Lehman's bankruptcy}

Based on (Brunnermeier2009), News feeds, Wikipedia

\begin{tabular}{|c|c|}
\hline Date & Events \\
\hline L-6 & - US Government's plan to bail out Fannie Mae and Freddie Mac leaks \\
\hline L-3 & $\begin{array}{l}\text { - OPEC will cut oil production by 500,000 barrels a day } \\
\text { - Announcement of the worst losses of Lehman }\end{array}$ \\
\hline L-1 & $\begin{array}{l}\text { - The Federal Reserve tries to find buyers for Lehman and warns CME of a potential } \\
\text { default }\end{array}$ \\
\hline $\mathrm{L}$ & $\begin{array}{l}\text { - Lehman files for bankruptcy in the morning, by lack of buyers and of bail out } \\
\text { - Merrill Lynch is sold to Bank of America }\end{array}$ \\
\hline $\mathrm{L}+1$ & - AIG is bailed out \\
\hline $\mathrm{L}+2$ & - Russia helps its biggest banks \\
\hline $\mathrm{L}+3$ & $\begin{array}{l}\text { - Russia extends help } \\
\text { - Lloyds TSB purchases HBOS, largely exposed to subprime mortgages }\end{array}$ \\
\hline $\mathrm{L}+4$ & $\begin{array}{l}\text { - The Troubled Asset Relief Program leaks } \\
\text { - US Treasury guarantees money market mutual funds up to } \$ 50 \text { billion } \\
\text { - Nigerian oil production is cut by } 280,000 \text { barrels per day and a pipeline of Royal } \\
\text { Dutch Shell has been destroyed }\end{array}$ \\
\hline $\mathrm{L}+5$ & - G7 commits to protect the financial system \\
\hline $\mathrm{L}+9$ & $\begin{array}{l}\text { - Washington Mutual is sold to JPMorgan Chase by the Federal Deposit Insurance } \\
\text { Corporation }\end{array}$ \\
\hline
\end{tabular}

Table 5: Important events around Lehman Brothers' bankruptcy (L denotes the date of Lehman's default, on September 15 ${ }^{\text {th }}, 2008$ ) 


\section{B Results}

\section{B.1 The Subprime crisis (August ${ }^{t h}, 2007$ )}

\section{B.1.1 Essential measures in spatial dimension at the Subprime crisis}

\begin{tabular}{rrrrrr}
\hline Date & $\begin{array}{r}\text { Average } \\
\text { Correlation }\end{array}$ & $\begin{array}{r}\text { Normalised } \\
\text { Length }\end{array}$ & $\begin{array}{r}\text { Survival } \\
\text { Ratio }\end{array}$ & $\begin{array}{r}\text { Allometric } \\
\text { Coefficient }\end{array}$ & $\begin{array}{r}\text { Length } \\
\text { Variation }\end{array}$ \\
\hline $7 / 26 / 07$ & 0.284565 & 1.171891 & $100.000 \%$ & 1.548404 & $-0.1282 \%$ \\
$7 / 27 / 07$ & 0.284928 & 1.170791 & $92.3077 \%$ & 1.535677 & $-0.0938 \%$ \\
$7 / 30 / 07$ & 0.283723 & 1.171836 & $100.000 \%$ & 1.535677 & $0.0893 \%$ \\
$7 / 31 / 07$ & 0.283426 & 1.172022 & $100.000 \%$ & 1.535677 & $0.0158 \%$ \\
$8 / 1 / 07$ & 0.284626 & 1.170999 & $100.000 \%$ & 1.535677 & $-0.0872 \%$ \\
$8 / 2 / 07$ & 0.28464 & 1.171014 & $100.000 \%$ & 1.535677 & $0.0013 \%$ \\
$8 / 3 / 07$ & 0.286562 & 1.169631 & $100.000 \%$ & 1.535677 & $-0.1181 \%$ \\
$8 / 6 / 07$ & 0.287167 & 1.16908 & $100.000 \%$ & 1.535677 & $-0.0472 \%$ \\
$8 / 7 / 07$ & 0.285501 & 1.170718 & $100.000 \%$ & 1.535677 & $0.1402 \%$ \\
$8 / 8 / 07$ & 0.286074 & 1.170403 & $100.000 \%$ & 1.535677 & $-0.027 \%$ \\
$\mathbf{8} / \mathbf{9} / \mathbf{0 7}$ & $\mathbf{0 . 2 8 4 5 8 7}$ & $\mathbf{1 . 1 7 1 8 4 1}$ & $\mathbf{9 2 . 3 0 7 7 \%}$ & $\mathbf{1 . 5 6 7 5 6 8}$ & $\mathbf{0 . 1 2 2 9 \%}$ \\
$8 / 10 / 07$ & 0.279291 & 1.175601 & $100.000 \%$ & 1.567568 & $0.3209 \%$ \\
$8 / 13 / 07$ & 0.279481 & 1.175498 & $100.000 \%$ & 1.567568 & $-0.0088 \%$ \\
$8 / 14 / 07$ & 0.275828 & 1.178507 & $92.3077 \%$ & 1.564295 & $0.256 \%$ \\
$8 / 15 / 07$ & 0.2757 & 1.178596 & $100.000 \%$ & 1.564295 & $0.0075 \%$ \\
$8 / 16 / 07$ & 0.279328 & 1.175142 & $92.3077 \%$ & 1.534996 & $-0.293 \%$ \\
$8 / 17 / 07$ & 0.279706 & 1.174629 & $92.3077 \%$ & 1.564295 & $-0.0437 \%$ \\
$8 / 20 / 07$ & 0.279477 & 1.174878 & $100.000 \%$ & 1.564295 & $0.0212 \%$ \\
$8 / 21 / 07$ & 0.280741 & 1.17366 & $100.000 \%$ & 1.564295 & $-0.1037 \%$ \\
$8 / 22 / 07$ & 0.282252 & 1.172409 & $100.000 \%$ & 1.564295 & $-0.1066 \%$ \\
$8 / 23 / 07$ & 0.281155 & 1.17345 & $100.000 \%$ & 1.564295 & $0.0888 \%$ \\
\hline
\end{tabular}

Table 6: Essential measures in spatial dimension around the Subprime crisis 
B.1.2 Essential measures in three dimensions at the Subprime crisis

\begin{tabular}{rrrrrr}
\hline Date & $\begin{array}{r}\text { Average } \\
\text { Correlation }\end{array}$ & $\begin{array}{r}\text { Normalised } \\
\text { Length }\end{array}$ & $\begin{array}{r}\text { Survival } \\
\text { Ratio }\end{array}$ & $\begin{array}{r}\text { Allometric } \\
\text { Coefficient }\end{array}$ & $\begin{array}{r}\text { Length } \\
\text { Variation }\end{array}$ \\
\hline $7 / 26 / 07$ & 0.935444 & 0.228957 & $99.087 \%$ & 1.741891 & $-0.254 \%$ \\
$7 / 27 / 07$ & 0.935353 & 0.228603 & $98.630 \%$ & 1.741784 & $-0.155 \%$ \\
$7 / 30 / 07$ & 0.935236 & 0.228814 & $100.000 \%$ & 1.741784 & $0.092 \%$ \\
$7 / 31 / 07$ & 0.935151 & 0.228857 & $100.000 \%$ & 1.741784 & $0.019 \%$ \\
$8 / 1 / 07$ & 0.934957 & 0.229496 & $99.087 \%$ & 1.743495 & $0.280 \%$ \\
$8 / 2 / 07$ & 0.934956 & 0.229595 & $99.543 \%$ & 1.749503 & $0.043 \%$ \\
$8 / 3 / 07$ & 0.934973 & 0.229577 & $99.543 \%$ & 1.743495 & $-0.008 \%$ \\
$8 / 6 / 07$ & 0.934897 & 0.229612 & $100.000 \%$ & 1.743495 & $0.015 \%$ \\
$8 / 7 / 07$ & 0.934735 & 0.229825 & $100.000 \%$ & 1.743495 & $0.093 \%$ \\
$8 / 8 / 07$ & 0.934709 & 0.229715 & $99.543 \%$ & 1.746068 & $-0.048 \%$ \\
$8 / \mathbf{9} / \mathbf{0 7}$ & $\mathbf{0 . 9 3 4 1 8 2}$ & $\mathbf{0 . 2 3 0 4 1 9}$ & $\mathbf{9 8 . 1 7 4 \%}$ & $\mathbf{1 . 7 5 0 2 9 2}$ & $\mathbf{0 . 3 0 7 \%}$ \\
$8 / 10 / 07$ & 0.933427 & 0.230842 & $98.174 \%$ & 1.754181 & $0.184 \%$ \\
$8 / 13 / 07$ & 0.933331 & 0.231053 & $100.000 \%$ & 1.754181 & $0.091 \%$ \\
$8 / 14 / 07$ & 0.933472 & 0.230955 & $99.543 \%$ & 1.754359 & $-0.043 \%$ \\
$8 / 15 / 07$ & 0.933366 & 0.231277 & $98.630 \%$ & 1.755655 & $0.139 \%$ \\
$8 / 16 / 07$ & 0.933937 & 0.229961 & $98.630 \%$ & 1.749886 & $-0.569 \%$ \\
$8 / 17 / 07$ & 0.933691 & 0.230512 & $99.087 \%$ & 1.748724 & $0.240 \%$ \\
$8 / 20 / 07$ & 0.933773 & 0.230256 & $99.543 \%$ & 1.749874 & $-0.111 \%$ \\
$8 / 21 / 07$ & 0.933796 & 0.230206 & $100.000 \%$ & 1.749874 & $-0.022 \%$ \\
$8 / 22 / 07$ & 0.934056 & 0.229894 & $99.087 \%$ & 1.750897 & $-0.135 \%$ \\
$8 / 23 / 07$ & 0.934068 & 0.230026 & $100.000 \%$ & 1.750897 & $0.057 \%$ \\
\hline & & & & &
\end{tabular}

Table 7: Essential measures in 3D around the Subprime crisis 


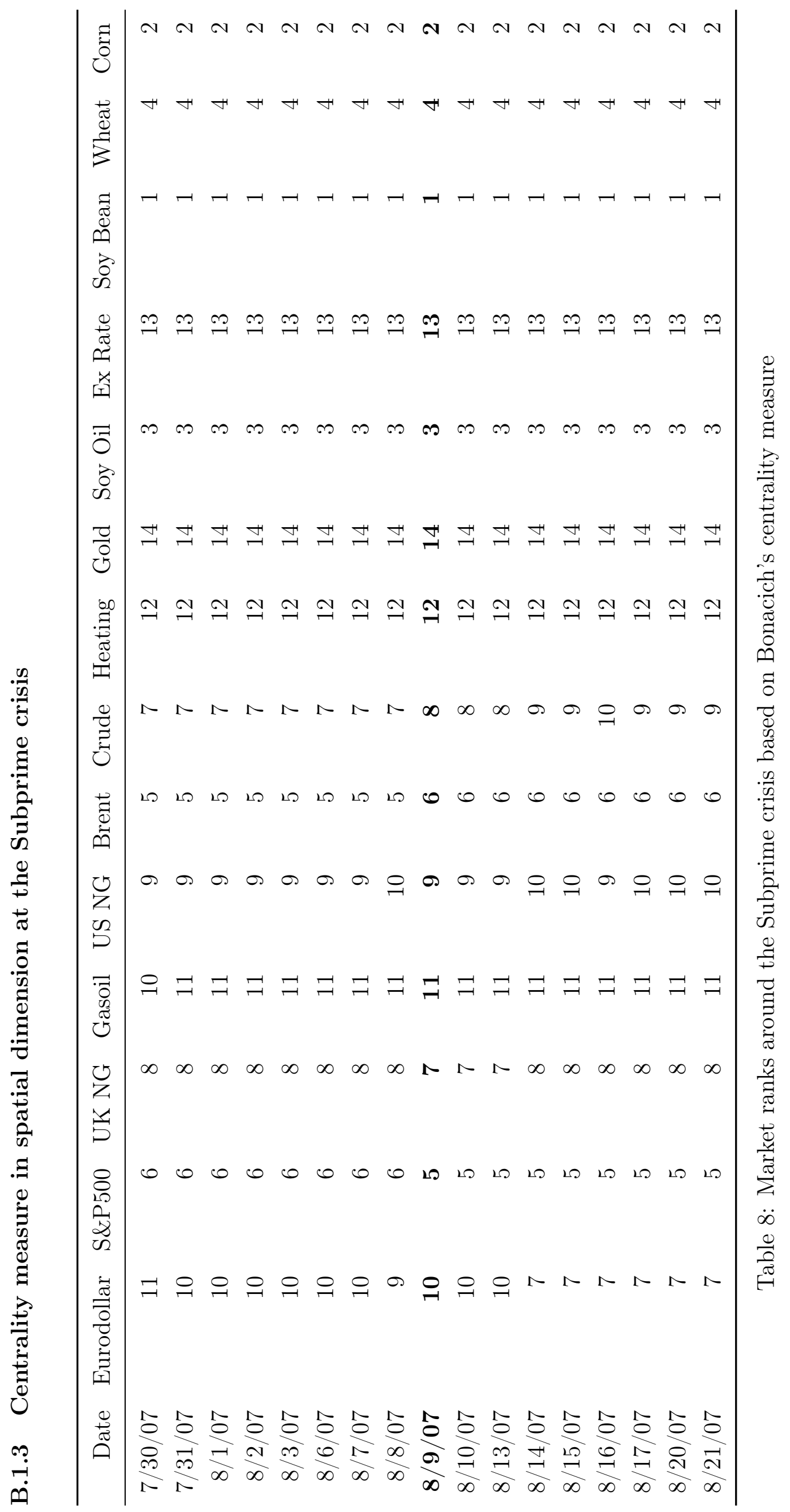




\section{B.2 The Lehman crisis (September $15^{\text {th }}, 2008$ )}

\section{B.2.1 Essential measures in spatial dimension}

\begin{tabular}{rrrrrr}
\hline Date & $\begin{array}{r}\text { Average } \\
\text { Correlation }\end{array}$ & $\begin{array}{r}\text { Normalized } \\
\text { Length }\end{array}$ & $\begin{array}{r}\text { Survival } \\
\text { Ratio }\end{array}$ & $\begin{array}{r}\text { Allometric } \\
\text { Coefficient }\end{array}$ & $\begin{array}{r}\text { Length } \\
\text { Variation }\end{array}$ \\
\hline $8 / 29 / 08$ & 0.541083 & 0.897748 & $92.308 \%$ & 1.544105 & $0.166 \%$ \\
$9 / 2 / 08$ & 0.543235 & 0.895739 & $100.000 \%$ & 1.544105 & $-0.224 \%$ \\
$9 / 3 / 08$ & 0.543926 & 0.894854 & $100.000 \%$ & 1.544105 & $-0.099 \%$ \\
$9 / 4 / 08$ & 0.54417 & 0.894513 & $100.000 \%$ & 1.544105 & $-0.038 \%$ \\
$9 / 5 / 08$ & 0.544865 & 0.893601 & $100.000 \%$ & 1.544105 & $-0.102 \%$ \\
$9 / 8 / 08$ & 0.546623 & 0.892112 & $100.000 \%$ & 1.544105 & $-0.167 \%$ \\
$9 / 9 / 08$ & 0.54791 & 0.89087 & $100.000 \%$ & 1.544105 & $-0.139 \%$ \\
$9 / 10 / 08$ & 0.547825 & 0.890786 & $100.000 \%$ & 1.544105 & $-0.010 \%$ \\
$9 / 11 / 08$ & 0.547522 & 0.891274 & $92.308 \%$ & 1.537859 & $0.055 \%$ \\
$9 / 12 / 08$ & 0.532962 & 0.912632 & $100.000 \%$ & 1.537859 & $2.396 \%$ \\
$\mathbf{9 / 1 5 / 0 8}$ & $\mathbf{0 . 5 2 9 9 5 7}$ & $\mathbf{0 . 9 1 6 1 3 4}$ & $\mathbf{1 0 0 . 0 0 0 \%}$ & $\mathbf{1 . 5 1 7 5 3}$ & $\mathbf{0 . 3 8 4 \%}$ \\
$9 / 16 / 08$ & 0.53218 & 0.91314 & $92.308 \%$ & 1.523825 & $-0.327 \%$ \\
$9 / 17 / 08$ & 0.524941 & 0.917529 & $84.615 \%$ & 1.545948 & $0.481 \%$ \\
$9 / 18 / 08$ & 0.524592 & 0.918997 & $76.923 \%$ & 1.549787 & $0.160 \%$ \\
$9 / 19 / 08$ & 0.52242 & 0.922051 & $69.231 \%$ & 1.532711 & $0.332 \%$ \\
$9 / 22 / 08$ & 0.522341 & 0.922852 & $92.308 \%$ & 1.515187 & $0.087 \%$ \\
$9 / 23 / 08$ & 0.521768 & 0.92969 & $92.308 \%$ & 1.513331 & $0.741 \%$ \\
$9 / 24 / 08$ & 0.52131 & 0.93029 & $92.308 \%$ & 1.49168 & $0.065 \%$ \\
$9 / 25 / 08$ & 0.52186 & 0.930091 & $100.000 \%$ & 1.49168 & $-0.021 \%$ \\
$9 / 26 / 08$ & 0.521898 & 0.929988 & $100.000 \%$ & 1.49168 & $-0.011 \%$ \\
$9 / 29 / 08$ & 0.52276 & 0.928977 & $100.000 \%$ & 1.49168 & $-0.109 \%$ \\
\hline & & & & &
\end{tabular}

Table 9: Essential measures in spatial dimension at Lehman 


\section{B.2.2 Essential measures in three dimensions at Lehman}

\begin{tabular}{rrrrrr}
\hline Date & $\begin{array}{r}\text { Average } \\
\text { Correlation }\end{array}$ & $\begin{array}{r}\text { Normalized } \\
\text { Length }\end{array}$ & $\begin{array}{r}\text { Survival } \\
\text { Ratio }\end{array}$ & $\begin{array}{r}\text { Allometric } \\
\text { Coefficient }\end{array}$ & $\begin{array}{r}\text { Length } \\
\text { Variation }\end{array}$ \\
\hline 8/29/08 & 0.953194 & 0.188464 & $99.543 \%$ & 1.754944 & $0.150 \%$ \\
$9 / 2 / 08$ & 0.953123 & 0.188775 & $99.543 \%$ & 1.768641 & $0.165 \%$ \\
$9 / 3 / 08$ & 0.953079 & 0.188726 & $99.087 \%$ & 1.757973 & $-0.026 \%$ \\
$9 / 4 / 08$ & 0.953079 & 0.188531 & $99.543 \%$ & 1.75763 & $-0.103 \%$ \\
$9 / 5 / 08$ & 0.953399 & 0.187443 & $98.630 \%$ & 1.758217 & $-0.577 \%$ \\
$9 / 8 / 08$ & 0.953282 & 0.187412 & $99.543 \%$ & 1.759045 & $-0.017 \%$ \\
$9 / 9 / 08$ & 0.953395 & 0.18718 & $99.543 \%$ & 1.758217 & $-0.124 \%$ \\
$9 / 10 / 08$ & 0.953393 & 0.187128 & $98.174 \%$ & 1.763128 & $-0.028 \%$ \\
$9 / 11 / 08$ & 0.953352 & 0.187199 & $99.087 \%$ & 1.760598 & $0.038 \%$ \\
$9 / 12 / 08$ & 0.952692 & 0.188793 & $98.174 \%$ & 1.758727 & $0.852 \%$ \\
$\mathbf{9} / \mathbf{1 5} / \mathbf{0 8}$ & $\mathbf{0 . 9 5 2 5 1 2}$ & $\mathbf{0 . 1 8 9 0 6 9}$ & $\mathbf{9 9 . 5 4 3 \%}$ & $\mathbf{1 . 7 5 6 0 8 9}$ & $\mathbf{0 . 1 4 6 \%}$ \\
$9 / 16 / 08$ & 0.952667 & 0.189008 & $97.717 \%$ & 1.759222 & $-0.032 \%$ \\
$9 / 17 / 08$ & 0.953348 & 0.186968 & $95.890 \%$ & 1.777651 & $-1.079 \%$ \\
$9 / 18 / 08$ & 0.9538 & 0.185915 & $98.174 \%$ & 1.775697 & $-0.564 \%$ \\
$9 / 19 / 08$ & 0.953401 & 0.186318 & $97.717 \%$ & 1.771135 & $0.217 \%$ \\
$9 / 22 / 08$ & 0.953281 & 0.186646 & $99.543 \%$ & 1.772232 & $0.176 \%$ \\
$9 / 23 / 08$ & 0.953175 & 0.187163 & $98.630 \%$ & 1.777591 & $0.277 \%$ \\
$9 / 24 / 08$ & 0.953228 & 0.187033 & $97.260 \%$ & 1.776397 & $-0.070 \%$ \\
$9 / 25 / 08$ & 0.953176 & 0.187069 & $97.717 \%$ & 1.770727 & $0.019 \%$ \\
$9 / 26 / 08$ & 0.953247 & 0.186929 & $99.543 \%$ & 1.768847 & $-0.075 \%$ \\
$9 / 29 / 08$ & 0.953293 & 0.18689 & $98.630 \%$ & 1.755138 & $-0.021 \%$ \\
\hline
\end{tabular}

Table 10: Essential measures in 3D around Lehman 


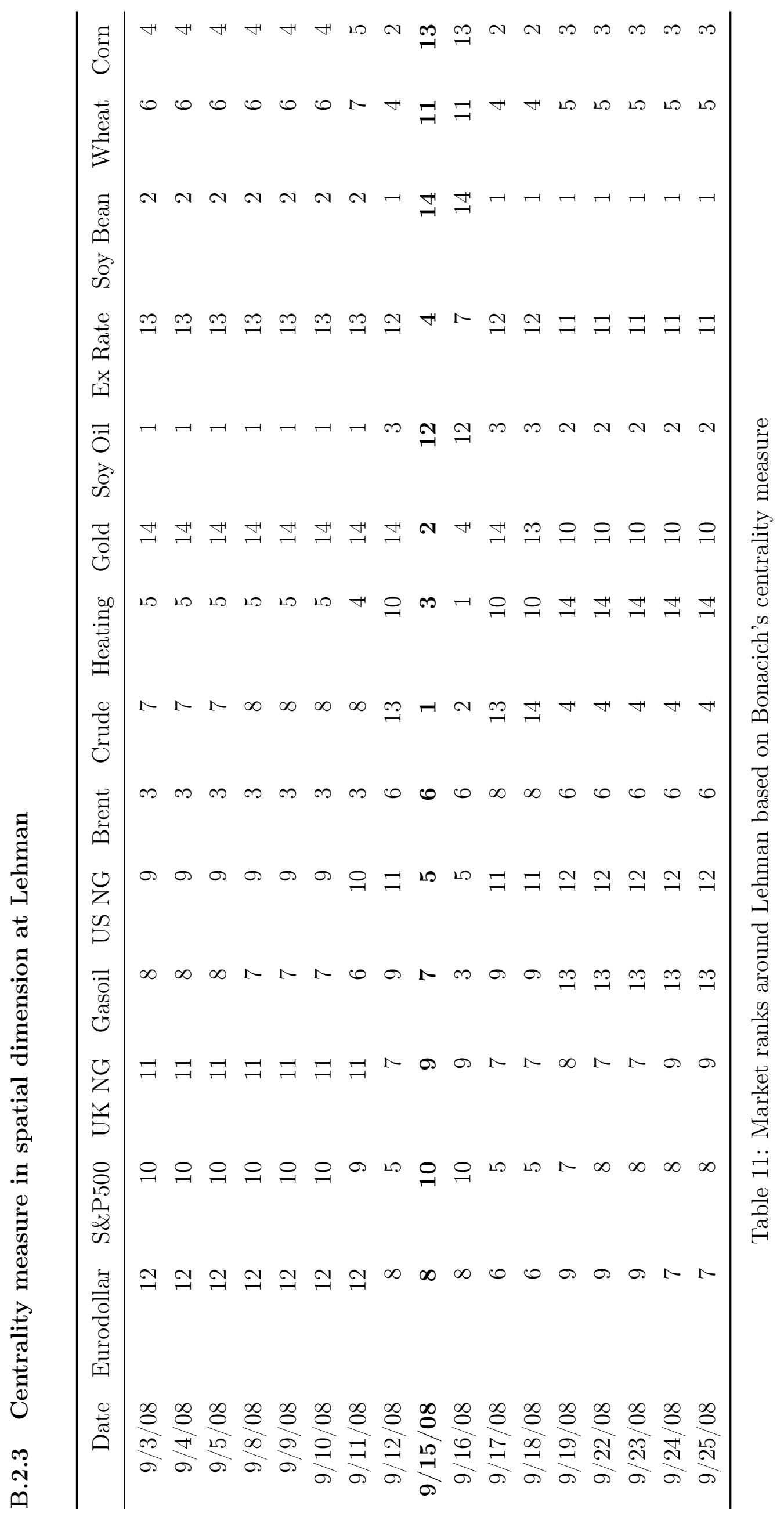

